\title{
A Case of Histoplasma duboisii Brain Abscess and Review of the Literature
}

\author{
Landry Konan ${ }^{1}$, Landry Drogba ${ }^{2}$, Doukoure Brahima ${ }^{3}$, Fassil B. Mesfin ${ }^{4}$ \\ 1. Anatomy and Neurosurgery, University Felix Houphouet Boigny, Abidjan, CIV 2. Neurosurgery, School of Medicine \\ at the University of Abidjan, Abidjan, CIV 3. Pathology, School of Medicine at the University of Abidjan, Abidjan, CIV 4. \\ Neurosurgery, University of Missouri, Columbia, USA
}

Corresponding author: Fassil B. Mesfin, mesfinf@health.missouri.edu

\begin{abstract}
Histoplasmosis is a fungal disease caused by Histoplasma capsulatum var. capsulatum (Hcc) and $H$. capsulatum var. duboisii (Hcd). Central nervous system (CNS) involvement is rare. So far, the few cases reported having Histoplasmosis associated brain abscesses were caused by $H$. capsulatum var. capsulatum. Herein, we report a unique case of brain abscess caused by H. capsulatum var. duboisii occurring in a 42year-old immunocompromised woman with HIV. Initially, she presented with hypothermia, vomiting, frontal headache, evolving over one month. She then progressed to have a generalized seizure. Brain MRI showed multifocal brain abscesses and a frontal osteitis. The frontal osteitis was biopsied and confirmed the diagnosis of $H$. capsulatum var. duboisii. She was successfully treated with liposomal amphotericin B (150 mg daily) for the first four weeks and itraconazole (200mg twice daily) for six months.
\end{abstract}

Categories: Neurology, Infectious Disease, Neurosurgery

Keywords: brain abscess, histoplasma duboisii, histoplasmosis, mycotic disease, histoplasma capsulatum, capsulatum, duboisii

\section{Introduction}

Histoplasmosis is a fungal disease caused by Histoplasma capsulatum var. capsulatum (Hcc) and H. capsulatum var. duboisii (Hcd). While the variant capsulatum is prevalent in the American continent, the variant duboisii is commonly reported endemically in western and Central Africa. Central nervous system (CNS) involvement is rare, and when it occurs, its typical presentation is meningitis [1-2]. So far, few cases of Histoplasmosis associated brain abscesses have been reported; they were all caused by $H$. capsulatum var. capsulatum. Herein, we reported a unique case of brain abscess by $H$. capsulatum var. duboisii occurring in an immunocompromised patient with HIV.

Received 01/27/2020

Review began 01/29/2020 Review ended 02/07/2020 Published 02/13/2020

\section{(c) Copyright 2020}

Konan et al. This is an open access article distributed under the terms of the Creative Commons Attribution License CC-BY 4.0., which permits unrestricted use, distribution, and reproduction in any medium, provided the original author and source are credited.

\section{Case Presentation}

A 42-year-old woman, a poultry-seller, was admitted to our institution for hypothermia, vomiting, frontal headache, evolving over one month. Generalized seizures complicated the symptoms three days before admission. The patient has a history of Hepatitis B and has been positive for HIV1 for five years but voluntarily stopped her antiretroviral treatment. Physical examination showed that she was conscious, emaciated, had oral candidiasis, and a frontal scalp swelling. No neurological deficits were noticed.

Laboratory results showed anemia $($ Hemoglobin $=10.5 \mathrm{~g} / \mathrm{dl})$, lymphopenia $\left(\right.$ Lymphocyte count $\left.=2.25^{*} 10^{3} / \mu \mathrm{L}\right)$ and a low $\mathrm{CD} 4+$ count of about 73 cells $/ \mathrm{mm}^{3}$. Tuberculosis screening by bronchopulmonary sputum, gastric sampling analysis, and chest X-ray was unremarkable.

A brain CT scan and MRI identified multifocal brain abscesses (frontal, cerebral, and cerebellar) associated with a frontal osteitis (Figure 1). The biopsy of the frontal lesion revealed a dark purulent fluid. Direct mycological analysis displayed several fungi with specific features evoking the diagnosis of Histoplasma capsulatum var. duboisii (Figure 2). 


\section{Cureus}
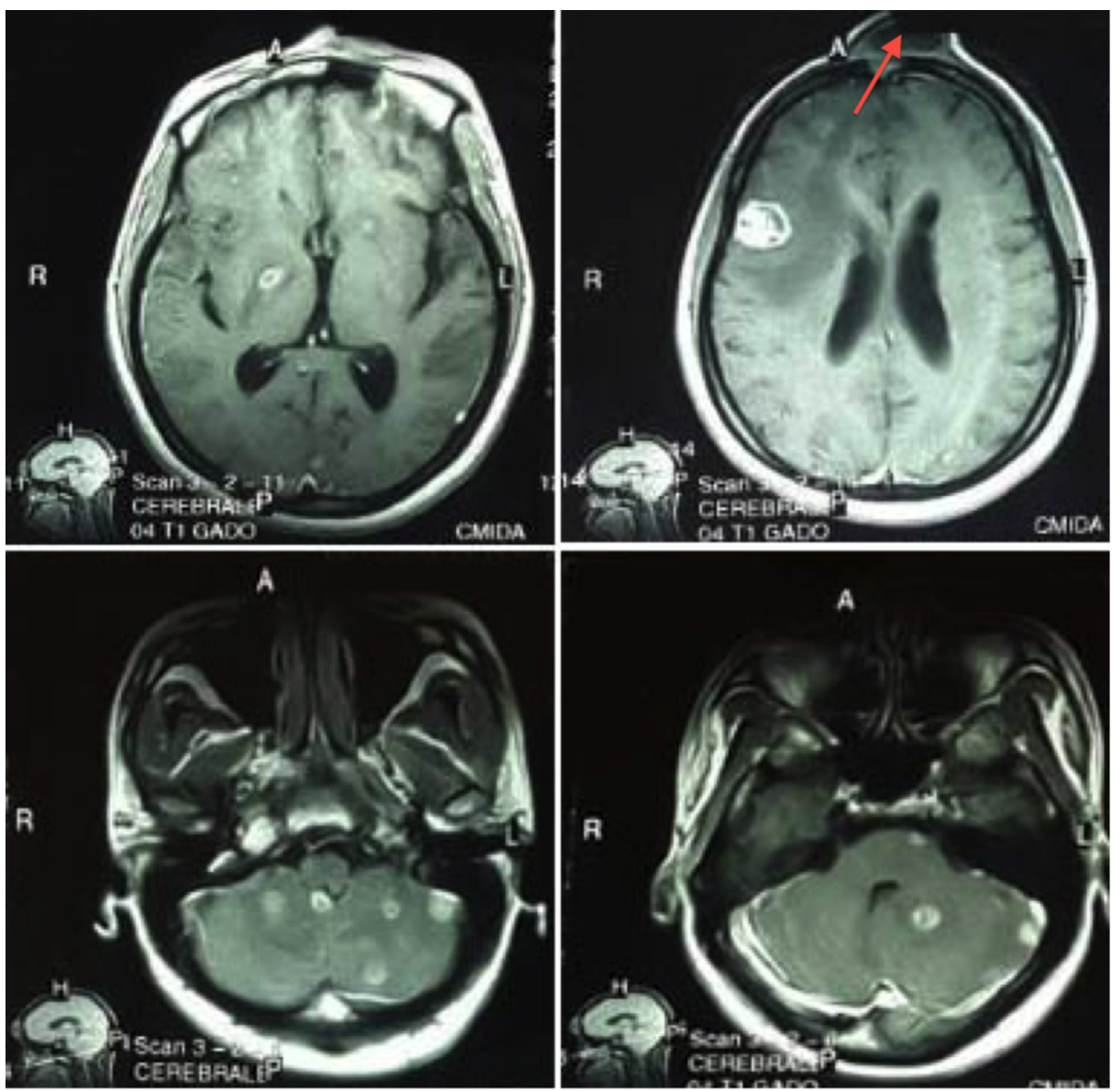

FIGURE 1: Gadolinium-enhanced MRI of the brain showing supra- and infratentorial round-shaped enhancing lesions and osteitis (red arrow)

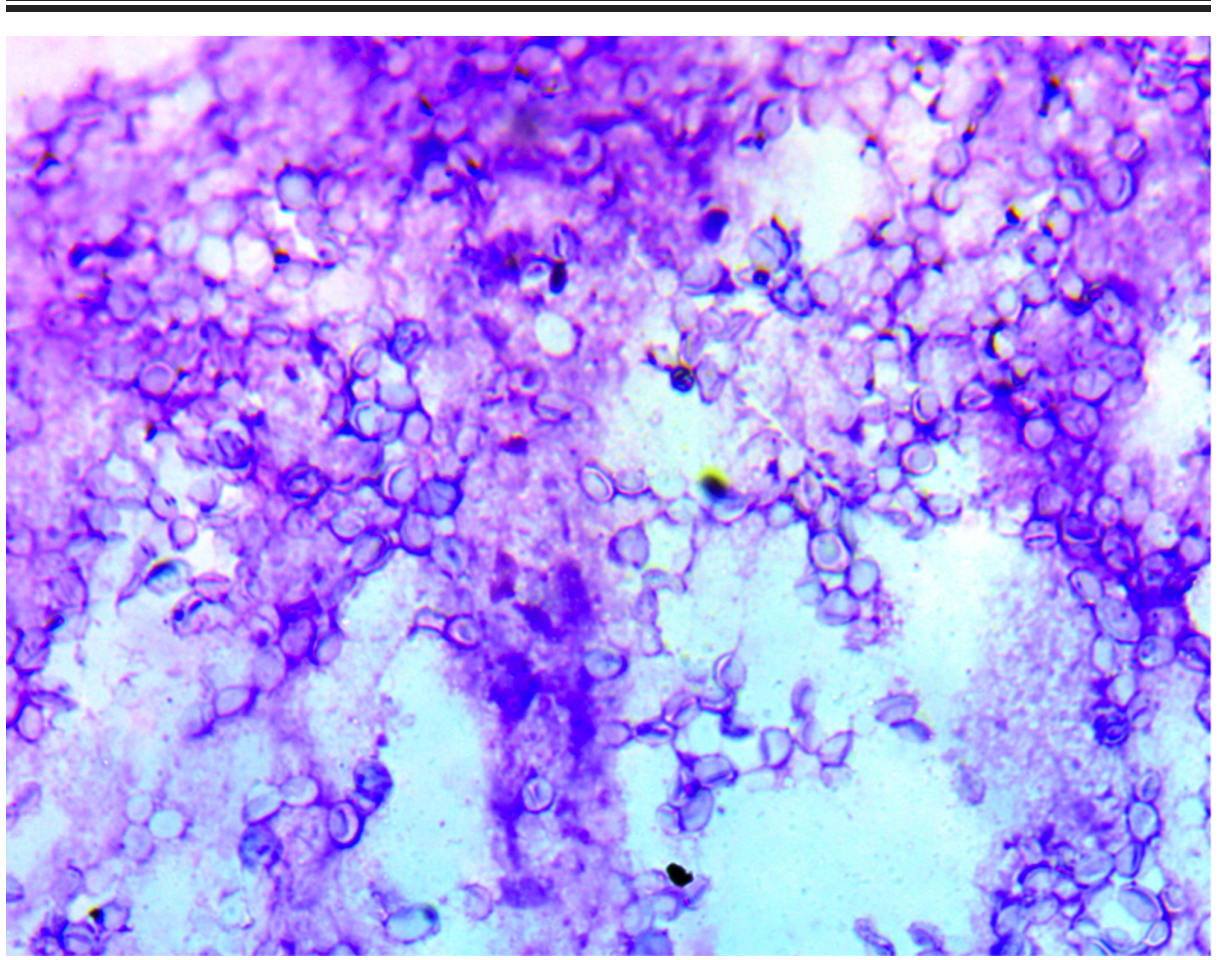

FIGURE 2: Direct examination of histoplasmosis (H. capsulatum var. duboisii) showing numerous intracellular yeasts with thick walls (May- 
The patient received an initial infusion of liposomal amphotericin B (150 mg daily) for the first four weeks of treatment. She started a new antiretroviral therapy. Subsequently, she was discharged with an oral dose of itraconazole (200mg twice daily) for six months. On the follow-up, eight months later, the patient was fine, and the post-therapeutic brain MRI and CT scan showed a resolution of brain abscesses. Consecutive followup examinations were scheduled every two months for one year.

\section{Discussion}

\section{Species}

Histoplasmosis is a fungal infection caused by two human pathogenic variants of Histoplasma capsulatum: var. capsulatum and var. duboisii. A third pathogenic variant has been described in the equine population. Since the initial description in 1952 by Dubois, the infection by the variant duboisii has been referred to as the African Histoplasmosis [3-6]. The yeast is found in soil and materials contaminated with bird or bat droppings. The reservoir of $H$. capsulatum var. duboisii is deemed to be in Africa as the published cases were reported from living in this continent, especially in West and Central Africa. The cases published from Spain and Japan were of African immigrants [6]. One exceptional case has been published in an autochthonous patient in India [4]. The disease is probably under-reported in Africa, where less than 300 cases have been published $[5,6]$. In the Ivory Coast, this is the sixth reported case, and to the best of our knowledge, this is the first African case of brain abscess [7].

\section{Pathogeny}

Although from the same species, the presentation and pathology of variants duboisii and capsulatum are variable. The variant capsulatum is endemic, not only in the United States around the Ohio and Mississippi River valleys but throughout the world, whereas the variant duboisii is limited to Africa [2]. On microscopy, the yeast cell sizes of variant duboisii are bigger, measuring $10-15 \mu \mathrm{m}$ versus $2-5 \mu \mathrm{m}$ for variant capsulatum $[4,6]$. Furthermore, the variant capsulatum is airborne, causing pulmonary infections, whereas the variant duboisii is involved in skin and bone infections [8]. The mechanism of the hematogenous dissemination of the infection to the meninges or brain is not well understood [9]. Some authors suggest that following inhalation of spores, the yeast forms thrive in the lungs and are initially controlled by helper T cells. In the case of T-cell immunodeficiency, the micro-organisms subsequently spread throughout the body via macrophages.

\section{Clinical presentation}

Published cases of CNS histoplasmosis were either meningitis, myelopathy, encephalitis, or focal parenchymal brain and spinal infections $[9,10]$. Some cases of stroke by infectious emboli and ventriculoperitoneal (VP) shunt infection have also been reported. CNS histoplasmosis occurs in $5-20 \%$ of disseminated infection, where T-cell immunodeficiency is a critical predisposing factor $[10,11]$. In our case, the patient was a poultry worker with untreated HIV infection. Therefore, her work environment, along with the HIV condition, made her be a typical vulnerable subject for CNS histoplasmosis. Multifocal supratentorial and infratentorial brain abscesses have been described in AIDS patients. However, those cases only involved the variant capsulatum [10-12].

African histoplasmosis frequently affects bony structures such as the vertebrae, skull, femur, and humerus. In our case, the patient had frontal osteitis, which allowed sampling and analysis of the purulent material.

\section{Diagnostic methods}

The diagnosis of African histoplasmosis relies on direct mycological examination, culture, and histopathological examination [4]. Although challenging, the culture of brain tissue and CSF provide the key evidence for the CNS infection [9]. Antigen detection sensitivity in cerebrospinal fluid (CSF) is reported in up to $67 \%$ in AIDS patients. Also, histopathology examination with Gomori methenamine silver or periodic acid-Schiff staining better visualizes the several large, thick-walled yeast cells seen mostly in histiocytic and giant cells [4].

\section{Therapeutic options}

CNS histoplasmosis can be a life-threatening condition. It is fatal if untreated. The therapeutic strategy is still controversial. Schestatsky et al. proposed a more aggressive induction phase with amphotericin B (40 $\mathrm{mg} / \mathrm{kg}$ ) for eight weeks [13]. One the other hand, the 2007 clinical practice guideline for histoplasmosis by Infectious Diseases Society of America (IDSA) advocated liposomal amphotericin B (5.0 mg/kg daily for a total of $175 \mathrm{mg} / \mathrm{kg}$ given over 4-6 weeks) followed by itraconazole ( $200 \mathrm{mg}$ two or three times daily) for one year and until resolution of CSF abnormalities, including Histoplasma antigen levels [14]. Since the blood levels of itraconazole may vary widely in patients, a close serum monitoring along with renal and hepatic 
function are advised to optimize the treatment. The optimal serum level in AIDS patients on antiretroviral therapy (ART) is unknown. However, one should remain mindful of a possible immune reconstitution inflammatory syndrome (IRIS) in those patients during the phase of the treatment [10].

Although cases of brain or spinal cord lesions excision have been documented, the indication of surgery is still unclear, especially in patients with multifocal brain lesions. Moreover, successful cases of CNS histoplasmosis treatment by antifungal agents alone have been published [15].

\section{Conclusions}

To the best of our knowledge, this case is the first case of cerebral localization of African histoplasmosis in the Ivory Coast and Africa. We believe this disease is still under-reported in our region. Since the advance in new immuno-suppressive drugs and the pandemic HIV infections, clinicians should expect to have more cases of CNS histoplasmosis. There is a need for personal protection equipment for individuals working in the poultry area. Further epidemiological analyses of national cases should lead to effective preventive actions by mapping of the possible reservoir of Histoplasma capsulatum var. duboisii.

\section{Additional Information \\ Disclosures}

Human subjects: Consent was obtained by all participants in this study. Conflicts of interest: In compliance with the ICMJE uniform disclosure form, all authors declare the following: Payment/services info: All authors have declared that no financial support was received from any organization for the submitted work. Financial relationships: All authors have declared that they have no financial relationships at present or within the previous three years with any organizations that might have an interest in the submitted work. Other relationships: All authors have declared that there are no other relationships or activities that could appear to have influenced the submitted work.

\section{References}

1. Starkey J, Moritani T, Kirby P: MRI of CNS fungal infections: review of aspergillosis to histoplasmosis and everything in between. Clin Neuroradiol. 2014, 24:217-30. 10.1007/s00062-014-0305-7

2. Bahr NC, Antinori S, Wheat LJ, Sarosi GA: Histoplasmosis infections worldwide: thinking outside of the Ohio river valley. Curr Trop Med Rep. 2015, 2:70-80. 10.1007/s40475-015-0044-0

3. Dubois A, Janssens PG, Brutsaert P, Vanbreuseghem R: [A case of African histoplasmosis; with a mycological note on Histoplasma duboisii n.sp]. Ann Soc Belg Med Trop (1920). 1952, 32:569-84.

4. Ravindran S, Sobhanakumari K, Celine M, Palakkal S: African histoplasmosis: the first report of an indigenous case in India. Int J Dermatol. 2015, 54:451-5. 10.1111/ijd.12683

5. Mabiala Babela JR, Mboutol Mandavo C, Nika Evrard R, et al.: [African histoplamosis. A report of three pediatric cases] (Article in French). J Mycol Med. 2017, 27:133-138. 10.1016/j.mycmed.2017.01.013

6. Valero C, Gago S, Monteiro MC, Alastruey-Izquierdo A, Buitrago MJ: African histoplasmosis: new clinical and microbiological insights. Med Mycol. 2017, 56:51-59. 10.1093/mmy/myx020

7. Oka DND, Mbende AS, Sissoko D: Spinal cord compression caused by multifocal histoplasmosis treated conservatively: case report and literature review. Open J Mod Neurosurg. 2016, 6:20. 10.4236/ojmn.2016.61004

8. Diadie S, Diatta B, Ndiaye M, et al.: Multifocal histoplasmosis due to Histoplasma capsulatum var. duboisii in a 22 year-old Senegalese patient without proven immunodepression (Article in French). J Mycol Med. 2016, 26:265-70. 10.1016/j.mycmed.2016.03.004

9. Hariri OR, Minasian T, Quadri SA, et al.: Histoplasmosis with deep CNS involvement: case presentation with discussion and literature review. J Neurol Surg Rep. 2015, 76:167-72. 10.1055/s-0035-1554932

10. Nyalakonda H, Albuerne M, Suazo Hernandez LP, et al.: Central nervous system Histoplasmosis in acquired immunodeficiency syndrome. Am J Med Sci. 2016, 351:177-86. 10.1016/j.amjms.2015.11.016

11. Andrade AI, Donato M, Previgliano C, Hardjasudarma H: Histoplasmosis brain abscesses in an immunocompetent adult: a case report and literature review.. Neuroradiol J. 2014, 27:334-8. 10.15274/NRJ2014-10038

12. Estrada-Bellmann I, Camara-Lemarroy CR, Flores-Cantu H, Calderon-Hernandez HJ, Villareal-Velazquez HJ: Hemichorea in a patient with HIV-associated central nervous system histoplasmosis . Int J STD AIDS. 2016, 27:75-7. 10.1177/0956462414564608

13. Schestatsky P, Chedid MF, Amaral OB, Unis G, Oliveira FM, Severo LC: Isolated central nervous system histoplasmosis in immunocompetent hosts: a series of 11 cases. Scand J Infect Dis. 2006, 38:43-8. 10.1080/00365540500372895

14. Wheat LJ, Freifeld AG, Kleiman MB, et al.: Clinical practice guidelines for the management of patients with histoplasmosis: 2007 update by the Infectious Diseases Society of America. Clin Infect Dis. 2007, 45:807-25. $10.1086 / 521259$

15. Kelly DR, Smith CD, McQuillen MP: Successful medical treatment of a spinal histoplasmoma . J Neuroimaging. 1994, 4:237-9. 10.1111/jon199444237 